\title{
Research on the Development of Construction and Economic Structure Coordination Degree of Shaanxi Province
}

\author{
Lijuan Zhang ${ }^{1}$ \\ Xijing University, 710123, Xi'an, China \\ e-mail: zhanglijuancpci@126.com
}

\author{
Xiaofang $\mathrm{Li}^{2}$ \\ Xijing University, 710123, Xi'an, China \\ e-mail: lixiaofangxijing@126.com
}

\begin{abstract}
The construction industry as a pillar industry of the national economy has an very important role in the coordinated operation of the national economy. Therefore, from the construction industry perspective, it is of great meaning for exploring the coordinated development of the economy. Based on the domestic and foreign researches of the relationship between construction industry and economic development, firstly, this article studies the construction industry and economic development status in Shaanxi Province. Secondly, the coupling coordination degree model is applied to analyze the change of Shaanxi construction industry and development of economy which has a rising trend. Finally, combining the achievement, a relative countermeasures for the research above should be presented.
\end{abstract}

Key words-Construction Industry, Economic Development, Coupling Coordination Degree, Shaanxi Province

\section{INTRODUCTION}

The construction industry as a pillar industry of the national economy has an very important role in the coordinated operation of the national economy. The rapid development of construction industry to strengthen the urban and rural infrastructure construction, promote the urbanization process, build a harmonious society and improve the efficiency of production in the whole society is of great significance [1]. As the pillar industry of national economy, the status of the construction industry in the national economy become to strengthen little by little, construction promoting the economic development is increasingly significant, there is a mutual influence, mutual promotion and mutual restriction relationship between them.

This article puts the coupling principle in physics into used to explore the coordinated development between the construction industry in Shaanxi province and Shaanxi province economic development problems[2]. On the basis of preliminary analysis in Shaanxi province construction and economic development at the status quo, and combined with the situation of Shaanxi province, build a system of the coupling coordination evaluation index between them, coupling criteria and coupling coordination degree model, then to judge the coupling coordination degree between the them, in order to in the construction industry as the breakthrough point,and promoting the coordinated development of Shaanxi economy.

Based on system science method guidance, through the industry economics, synergetics and development economics, and other multi-disciplinary theories and research methods, to research the coupling coordination relationship between construction and economic development of Shaanxi province. The construction industry as a pillar industry of the national economy has an very important role in the coordinated operation of the national economy. Therefore, from the construction industry perspective, it is of great meaning for exploring the coordinated development of the economy. Based on the domestic and foreign researches of the relationship between construction industry and economic development, first, this article studies the construction industry and economic development status in Shaanxi Province. Secondly, the coupling coordination degree model is applied to analyze the change of Shaanxi construction industry and development of economy has a rising trend. Last, combining the achievement, a relative countermeasures for the research above should be presented.

\section{The ESTABlishment OF The $G M(1,1)_{\mathrm{MODEL}}$}

To avoid the stochastic characteristics of the original sequence and provide useful information for the model, the original sequence is usually processed before establishing the grey prediction model.

The sequence is generally processed by conducting a continuous sum calculation[3].

Assume that there are $n$ points in the sequence $X^{(0)}$ :

$$
X^{(0)}=\left\{X^{(0)}(1), X^{(0)}(2), \cdots, X^{(0)}(n)\right\}
$$

A new sequence is generated by conducting a continuous sum calculation

$$
X^{(1)}=\left\{X^{(1)}(1), X^{(1)}(2), \cdots, X^{(1)}(n)\right\}
$$

The differential equation for model $\operatorname{GM}(1,1)$ is then derived as:

$$
\frac{d X^{(1)}}{d X}+a X^{(1)}=\mu
$$

Where $a$ is the grey figure and $\mu$ is the grey action.

Assume that $\alpha$ is a parameter vector whose value is to be assigned,

$$
\alpha=\left(\begin{array}{l}
a \\
\mu
\end{array}\right)
$$



that:

By applying the least square method, it can be derived

$$
B=\left(\begin{array}{cc}
\alpha=\left(B^{T} B\right)^{-1} B^{T} Y n & \text { Where } \\
-\frac{1}{2}\left[X^{(1)}(1)+X^{(1)}(2)\right] & 1 \\
-\frac{1}{2}\left[X^{(1)}(2)+X^{(1)}(3)\right] & 1 \\
\vdots & \vdots \\
-\frac{1}{2}\left[X^{(1)}(n-1)+X^{(1)}(n)\right] & 1
\end{array}\right),
$$
written

By solving the equation, the prediction model can be as:

$$
\hat{X}^{(1)}(k+1)=\left[X^{(0)}(1) \frac{\mu}{a}\right] e^{-a k}+\frac{\mu}{a}, k=0,1, \cdots, n(6)
$$

Calculate $\hat{X}^{(1)}(i)$ basing on the prediction model.

By conducting a continuous minus calculation for $\hat{X}^{(1)}(i)$, the predicted sequence $\hat{X}^{(0)}(i)$ is derived.

\section{THE ANALYSIS OF SHANXI PROVINCE CONSTRUCTION AND ECONOMIC DEVELOPMENT PRESENT SITUATION}

\section{A. The relevant concepts of construction and economic development}

When talking about the definition of the construction industry, there are broad and narrow definition. The broad construction mainly reflects its real economic activity space. Narrow construction belongs to the second industry, namely the classification standard of the national economy (GB/T4754-2002) in the construction industry[4].

This paper defines economic development that in a country or a region the growth process of the population average actual benefits, here mainly refers to the continuous growth of the economies of scale (such as GDP, total society fixed asset investment, total social retail product, fiscal revenue, etc.); the continuous optimization of economic structure (the proportion of the proportion of primary industry, secondary industry, the proportion of the tertiary industry, etc.); the continuous improving of economic benefits (such as per capital GDP and disposable income of urban residents and residents consumption price index, etc.).
B. The relationship between the construction and economic development

Hillebrandt[5]and Ruddock \& Lopes[6]in the study emphasis that in most developing countries, there are about half of the gross fixed capital formation from the construction industry, therefore, the construction industry plays a leading role in the national fixed capital formation. The national economic growth is the important factor in the development of construction industry, construction industry fluctuates pass by the national economic cycle fluctuation, and the construction industry will expand with economic growth.

The rapid development of construction industry to strengthen the urban and rural infrastructure construction, promote the urbanization process, build a harmonious society and improve the efficiency of production in the whole society is of great significance[7].During this period, 1996-2011 considered that Shaanxi province rapid economic development, and increasing the scale of construction, It is important to study the current situation of the development of construction industry in Shaanxi province.

Compared and analyzed the construction industry output value and growth and rate from 1996 to 2011, the period construction of Shaanxi province can be divided into three stages[8].

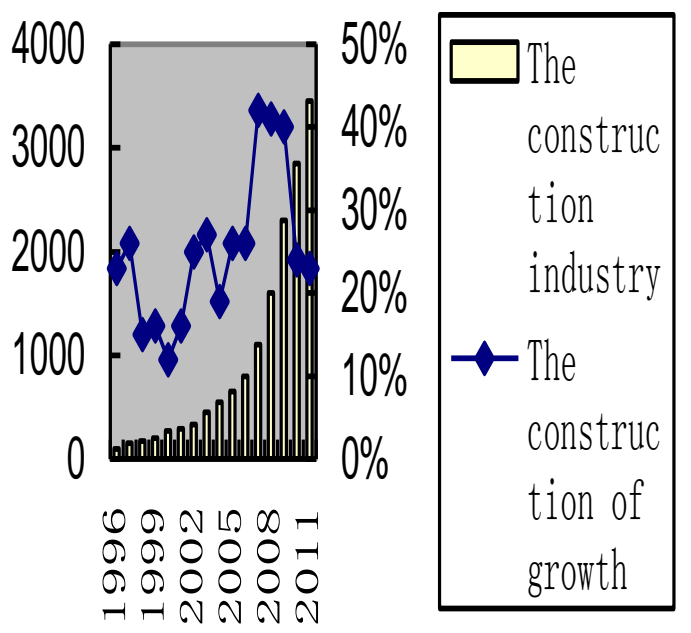

Fig1. The construction industry output value and growth in Shaanxi province

The first stage is from 1996 to 2000. It can be seen from the Fig. 1, the construction industry output value in Shaanxi province have been rising at this stage, but the construction industry growth was first to rise after falling.

The second stage is from 2000 to 2008 . Which can be seen from Fig. 1 the second stage the construction industry output value in Shaanxi province increased significantly fast, the curve is also present a degree of volatility.

The third stage is from 2008 to 2011. It can be seen from Fig. 1 that Shaanxi construction industry output value has been on the rise, however construction industry growth rate has dropped in this stage. 
C. The analyzed of the economy development present situation in Shaanxi province

In recent years, with the national related policy support and the strength of the reform and opening-up, the national economy development with high speed and the economy of Shaanxi is developing rapidly[9]. In 1996, the GDP of Shanxi province is 121.584 billion yuan, in 2011 GDP reached 1.25123 trillion yuan, just as shown in Fig2.From 1996 to 2011, contrasted and analyzed GDP and his growth in Shaanxi province, the period of Shaanxi economy can be divided into three stages.

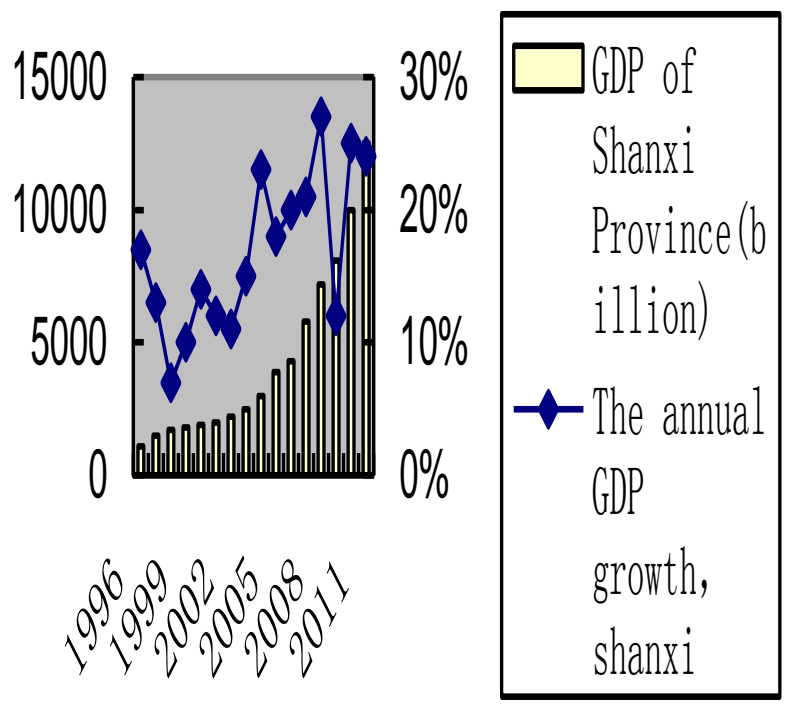

Fig 2. Shanxi province GDP growth

The first stage from 1996 to 1997 years, the GDP growth rate was decline.This is because the rising prices in China, such as serious inflation which economic growth too fast. And in 1997, our country's economy is affected by the Asian financial crisis, the market of economy in recession, therefore, this period of GDP in Shaanxi province is on the increase, however, the GDP growth rate has a decline trend.

The second stage that from 1998 to 2008 is in the growth stage. But in 2008, Shaanxi economy is affected by the global financial crisis and gross domestic product (GDP) growth rate has fallen dramatically, and economic development is affected.

The third stage that from 2009 to 2011 in the rapid growth. In 2009, the state investment is great, gross domestic product (GDP) began to pick up. Since 2010, Shaanxi province economic situation is good, but the investment power decreases, therefore, Shaanxi GDP growth stable.

\section{COORDINATION OF CONSTRUCTION AND ECONOMIC DEVELOPMENT IN SHANXI PROVINCE}

To realize the harmonious development of the construction and economic development is the foundation of a healthy and stable economy. In recent years, in the overall environment of China's economy high speed development, Shaanxi economy developing rapidly, especially the construction industry as one of the pillar industries of national economy and is sustained development of the situation.

In this paper, the development level is characterized by comparison of Shaanxi construction output rate and the gross domestic product (GDP) of Shaanxi province[10]. As can be seen from the Fig.3, 1996-2011 which Shaanxi province GDP and construction overall is on the rise.

Shaanxi province construction industry output value increased from 15.945 billion yuan in 1996 to 349.85 billion yuan in 2011, which increased by 27 times for 16 years.

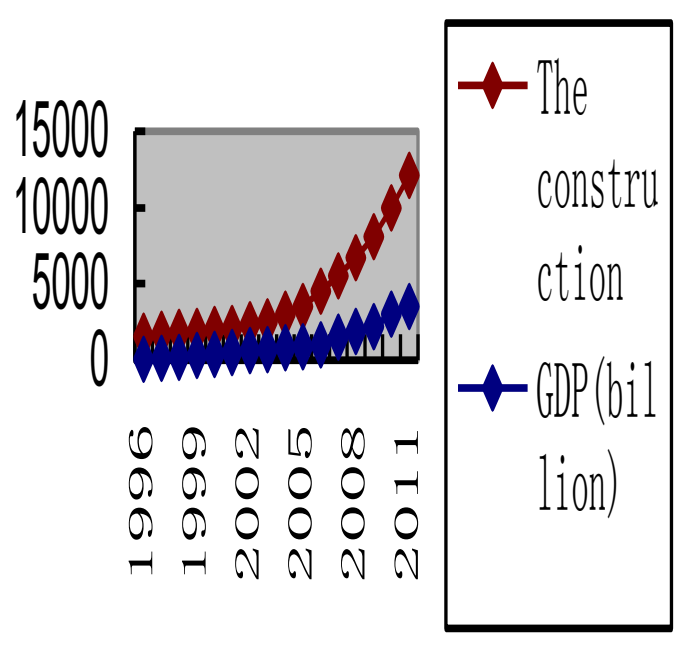

Fig 3. The trend of GDP and construction industry output value changes of Shanxi province

And GDP of Shaanxi province from 121.584 billion yuan in 1996 to 1.25123 trillion in 2011, which increased by 10 times in 16 years. Not only above that, during the study period that 1996-2005, Shaanxi construction and GDP all developed slow, since 2005, all of them began to rapid development, the speed is consistent. Thus, they two has strong correlation, and on the level of development has obvious coordination.

In this paper, from two aspects of development level and speed, the coordinated relationship between the construction and economic development of Shanxi province [11] is analyzed, which shows that the construction industry and economy on the level of development space is consistent, and on the develop speed has apparent incongruity.

\section{ACKNOWLEDGEMENTS}

This work is supported by 2013 scientific research project of Beifang University of Nationalities (No.2013XYZ021), institute of information and system computation science of Beifang University (No.13xyb01), Natural Science Foundation of Xijing University(No. XJ140210)

\section{REFERENCES}

[1] Chan, S. L.. Empirical tests to discern linkages between construction and other economics sectors in Singapore[J]. Construction Management and Economics,2001(19) : 355-363. 
[2] Chandan Sharma. Impact of infrastructure on output productivity and efficiency [J]. Indian Growth and Development Review 20102 100-121.

[3] Y.Jia, X.Y.Ji: The mathematical model and application in the field of economic practice, Vol.5, 2011, pp.79-81.

[4] Diao Xundi,Shen Liyin,Zeng Saixing,Ochoa Jose Jorge,Zhang Xiaoling. Relationship between energy consumption and economic development in construction industry[J]. Journal of Engineering, Design and Technology,2010,83:

[5] Hillebrandt,P.M.. Economic theory and the construction industry. Basingstoke, Hampshire : Macmillan, 2000.

[6] Hills, Martyn James,Fox, Paul William,Skitmore, Martin,Hon, Carol K H,Fong, Patrick Sik-Wah. The Role of Project Managers in Construction Industry Development $[\mathrm{J}]$. AACE International Transactions, 2008,:
[7] Kwabena Asomanin Anaman,Charity Osei-Amponsah. Analysis of the causality links between the growth of the construction industry and the growth of the macro-economy in Ghana[J]. Construction Management and Economics,2007,259:.

[8] Ruddock, L.,\&Lopes,J..The construction sector and economic development : the Bon curve $[\mathrm{J}]$. Construction Management and Economics, 2006, 24(7) : 717-723

[9] Yangfan Li,Yi Li,Yan Zhou,Yalou ShiXiaodong Zhu.Journal of Environmental Management [J]. 2012 (98) : 127-133.

[10] Zhang Aixia, Wang Junlin. Subgrade moisture content on the quality of the subgrade engineering Inner Mongolia highway and transportation. 2004

[11] Shuanghe Yu, Wenyi Qiang and Peichen Fu. Chattering-free Discrete Quasi-sliding Mode Controller. Control and Decision,

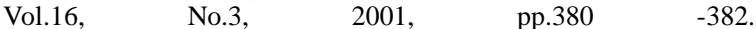

